\title{
ALTERAÇÕES DA JUNÇÃO NEUROMUSCULAR EM MIOPATIAS EXPERIMENTAIS NO CAMUNDONGO
}

\author{
LUIZ FERNANDO BLEGGI TORRES*
}

\begin{abstract}
RESUMO - As alteraçðes morfolósicas observadas em junção neuromuscular de dols modelos de miopatia em camundongos săo estudadas por métodos histoquímicos para demonstrar atividade da enzima acetilcolinesterase e por microscopia eletrônica. Em ambas as situaçôes os resultados obtidos são similares, indicando que a junçāo neuromuscular permanece intacta mesmo quando a fibra que inerva está sofrendo necrose. Em fibras musculares regeneradas há acentuada simplificação das pregas pós-sinápticas, com rédução de até 50\% dos valores normais, comprovado por estudos morfométricos. A ausência de repercussōes fisiológicas ou clínicas detectáveis nesses modelos, apesar da significativa hipotrofia da membrana pós-sináptica, sugere que a exuberante quantidade de pregas pós-sinápticas normalmente encontradas nas junçōes mioneurais pode representar mecanismo anatômico de segurança na transinissāo quimica neuromuscular.
\end{abstract}

The neuromuscular junction in experimental myopathies in the mouse.

SUMMARY - Morphological abnormalities of the neuromuscuiar junction in two murine models with primary myopathy were studied by combined cholinesterase-silver impregnation techniques and electron microscopy. In both situations the results were similar showing that the neuromuscular junction remained unafected even when inervating necrotic nuscie fibres. In regenerated muscle fibres, however, there was marked simplification of the post-synaptic membrane with reduction in number and depth of folds up to 50\% of normal values confirmed by morphometric analysis. Since after regeneration succeded no detectable clinical or physiological alterations were observed in these experiments it seenis reasonable to assume that the prominent branching of post-synaptic folds in normal skeletal muscles might represent an increased anatomical safety mechanism in chemical transmission.

A junção neuromuscular (JNM) é região especializada de transmissão do potencial de ação do nervo periférico para a musculatura esquelética. $O$ conhecimento de seus mecanismos de adaptação e plasticidade diante de diversas doenças neuromusculares permanece no campo especulativo. No presente estudo demonstramos alterações morfológicas significativas observadas na JNM de fibras musculares esqueléticas em dois modelos experimentais, o camundongo mutante ' $m d x$ ' portador de uma miopatia congênita 41 e camundongos tratados com fração fosfolipásica do veneno da serpente do mar Enhydrina schistosa 8.

\section{MATERIAL E METTODOS}

Animais - Um total de 29 camundongos ' $m d x$ ' com idades variando de 3 semanas a 12 meses e 27 camundongos C57B1/10 controles foram incluidos neste estudo. Além destes animais 24 camundongos $\mathrm{Balb} \mathrm{C}$ adultos receberam doses intramusculares de 0,03 microgramas de fosfolipase A2 derivada do veneno da serpente Enhydrina schistosa diluídos em $1 \mathrm{ml}$

* PhD, Professor Adjunto do Deyartamento de Patologia Médica, Hospital de Clínicas, Universidade Federal do Paraná. 
de solução de Ringer. Para respectivo grupo controle, 18 camundongos receberam solução de Ringer em iguais volumes. Todos os animais controles foram, dentro do possivel, ajustados para sexo e idade (39).

Demonstraçāo de atividade da enzima acetilcolinesterase — Foi realizada pelos métodos de Namba et al. (30) e de Pestronk e Drachman (39). Os animais profundamente anestesiados foram perfundidos pelo ventriculo esquerdo com formol-cálcio gelado. Os músculos gastrocnêmio, plantiris e soleus foram dissecados e retirados dos animais sendo cortados en criostato a 20 e 30 micrômetros e respectivamente corados pelos métodos do iodeto de acetiltiocolina e acetato de bromoindoxil para demonstrar a atividade da colinesterase, seguidos por impregnaçāo argêntica para axônios.

Microscopia eletrônica - Para estudos ultraestruturais o fixador utilizado foi soluçāo modificada de Karnovsky (26), por perfusão intracardíaca. Fragmentos de soleus foram pós-fixados em tetróxido de ósmio a 1\%, desidratados em álcool, processados e incluídos em araldite. Cortes longitudinais e transversais com 1 micrometro foram corados com azul de toluidina e, após seleção da área apropriada, os cortes ultrafinos obtidos foram corados com acetato de uranila e citrato de chumbo e observados em microscópio eletrônico JEOL 100CX com voltagem de aceleração de $80 \mathrm{kV}$.

Métodos morfométricos para JNM - A análise de um número de parâmetros definidos por Engel e Santa (15) e Santa e Engel (35) foi realizada em cortes ultrafinos de músculo soleus. Estes cortes foram ajustados no microscópio eletrônico para altura e magnificação constante e calibrados com uma gradícula padrão contendo 2160 linhas $/ \mathrm{mm}$. Cada JNM observada em cortes seriados a intervalos de 100 micrometros foi fotografada e as fotos ampliadas a magnificação final de 20000. Cada axônio terminal, considerado neste estudo como uma JNM individual, bem como sua respectiva membrana pós-sináptica, foram estudados com auxilio de analisador de imagem Kontron-MOP AM-3 ligado a microcomputador RML 3802 especialmente programado para este fim (39).

\section{RESULTADOS}

1. Aspectos normais da JNM - A inervação motora de fibras musculares extrafusai em camundongos tem várias similaridades com aquela observada em outras espécies de mamíferos (6). Nervos mistos sensitivo-motores penetram pelo hilo vásculo-nervoso e, após dividirem-se repetidamente, atingem a porçăo média entre a origem e inserção do músculo. Neste ponto os fascículos nervosos espalham-se num leque de fibras mielinizadas pré-terminais, cada uma das quais indo inervar uma única fibra muscular. O axônio pré-terminal perde sua capa de mielina e perıetra la JNM (também conhecida como placa terminal). Preparações demonstrando a atividade da enzima acetilcolinesterase (Fig. 1), a qual cuncentra-se normalmente nas goteiras đa JNM, permitem avaliaçāo adequada do pađrão de inervação motora muscular, bem como a estrutura do aparelho subneural de Couteaux (11), o qual varia em forma e tamanho conforme o tipo de fibra muscular a que pertença. Os principais aspectos ultraestruturais de JNM foram extensivamente revistos por diversos autores $(6,10,15,18,32)$. $O$ axônio terminal, contendo grande quantidade de vesículas sinápticas e mitocôndrias, repousa numa depressão da membrana sircolemal que é acentuadamente pregueada (Fig. 1). A superfície externa do axônio é recoberta por citoplasma da célula de Schwann e há grande quantidade de membrana basal preenchendo a goteira sináptica. Usualmente, observa-se aglomerado de núcleos e de organelas sarcoplasmáticas subjacentemente à JNM. Existem diferenças ultraestruturais entre JNM de fibras de contração lenta e rápida. Nas primeiras, os axônios terminais sāo menores e arredondados e o sarcoplasma da placa terminal contém maior quantidade de organelas e menor número de pregas pós-sinápticas $(9,12,22,42)$.

2. Alteraçôes na JNM observadas na fase aguda - Neste grupo enquadramos os animais 'mdx' jovens com predominio de lesōes musculares necrotizantes agudas e os camundongos Balb C tratados com fosfolipase A2 e estudados de 30 minutos a 48 horas após a injeção intramuscular da toxina. Portanto, todas as fibras musculares selecionadas apresentavam alteraçōes necróticas estabelecidas como desorganização de linhas $\mathbf{Z}$, formação de coágulas retracionais, degeneração mitocondrial, dilatação de retículo sarcoplasmático e ruptura de plasmalema. Tanto no camundongo mutante ' $m d x$ ' quanto nos animais tratados com fosfolipase A2 nảo se observou modificação no padrão de inervação dos múculos estudados, apesar de graus variados de necrose. Em nenhum estágio verificou-se aiteraçāo na distribuiçấo de axônios prê-terminais, os quais sempre inervavam fibras musculares individuais mesmo quando necróticas. Preparaçōes para demonstrar atividade da enzima acetilcolinesterase possibilitaram identificar, em ambas as situações estudadas, preservação da açāo desta enzima nos aparelhos subneurais, apesar de extensa necrose muscular subjacente (Fig. 2). A nível ultraestrutural 


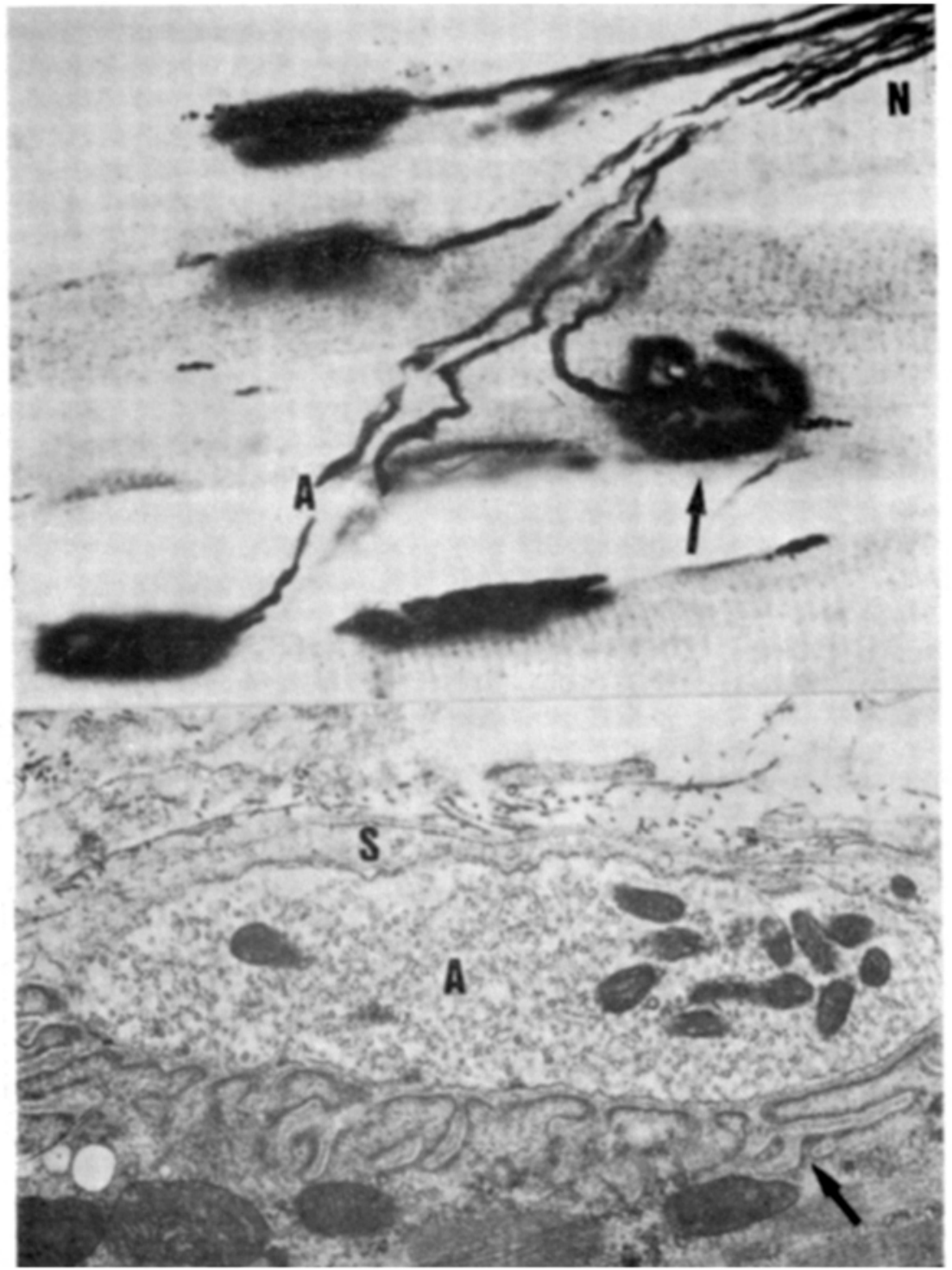

f. 1 - Em cima, corte por congelação de músculo da perna de camundongo corado para demonstrar acetilcolinesterase $e$ axônios pelo método de Pestronk e Drachman(33): nervo intramuscular ( $N$ ) divide-se em inúmeros axônios pré-terminais (A), os quais inervam fibras musculares individualmente; na junçäo neuromuscular, o aparelho subneural de Couteaux é indicado pela deposição de produto opaco azul escuro (seta); notar que o padrão normal é deposição contínua ao longo de todo o aparelho subneural $(\times 400)$. Em baixo, microscopia eletrônica de junção neuromuscular de soleus de comundongo adulto normal: axônio terminal (A), coberto por processos da célula de Schwann (S), repousa numa depressão da membrana sarcolemal a qual é acentuadamente pregueada (seta); o axônio terminal contém mitocôndrias $e$ vesículas sinápticas $e$, no sarcoplasma, observa-se acúmulo de mitocôndrias e reticulo endoplasmático $(\times 20000)$. 


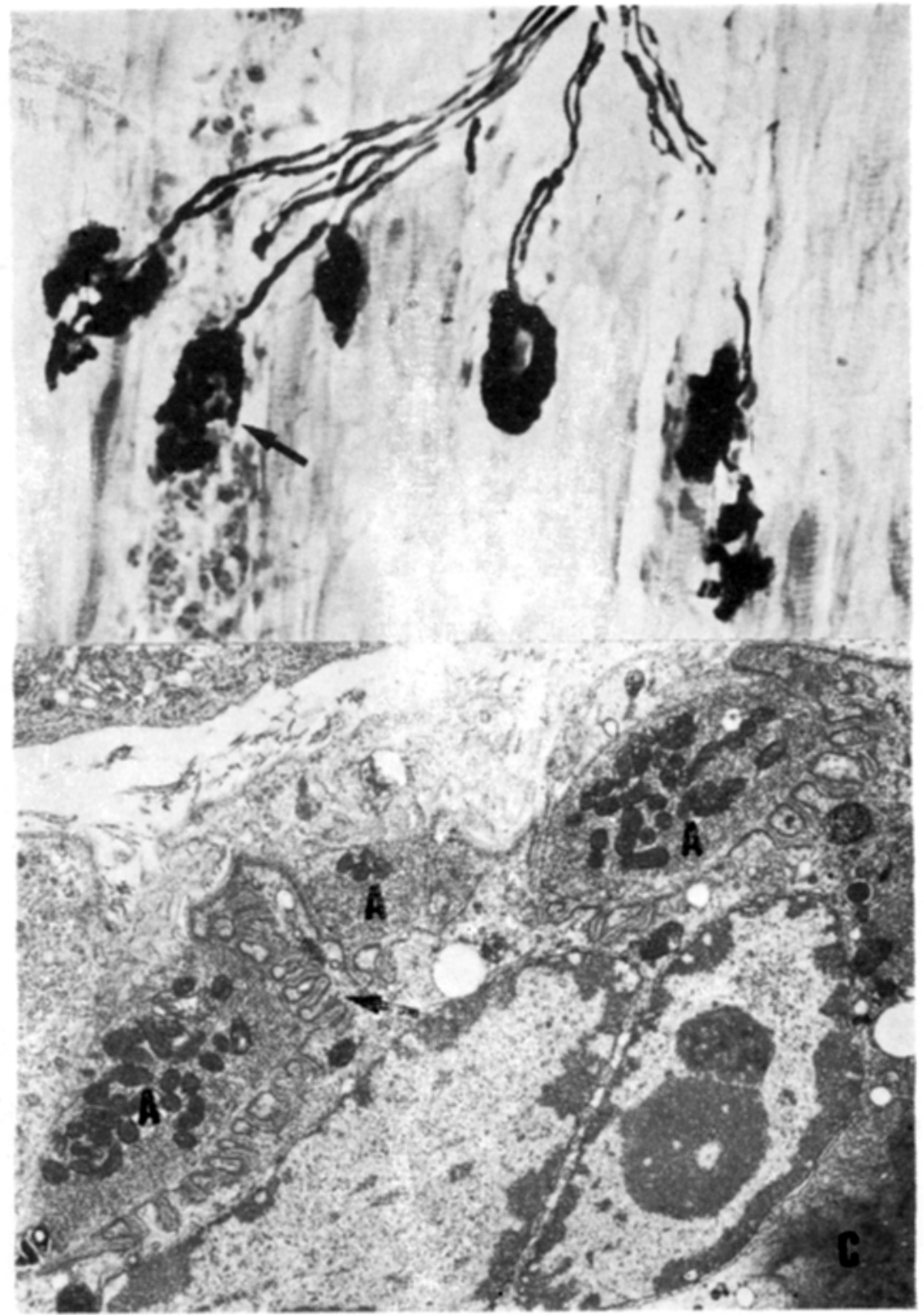

Fig. :- Em cima, preparasão para demonstrar acetilcolinesterase e axônios pelo método de Namba et al.(30) em músculo de camundongos tratados com 0,03 micrognamas de fosfo. lipase A2 48 horas após injeção intramuscular desta toxina; o padrão de inervaça permanece normal $e$, mesmo em fibras musculares necróticas, a atividade da enzima permanece visivel (seta) $(\times 300)$. Em baixo, m'croscopia eletrônica de junção neuromuscular em fibra necrótica pós-injeção de fosfolipase A2; apesar da acentuada desorganização da fibra que contém mitocôndrias anormais e coágulo retracional (C), o axônio terminal (A) permanece intacto bem como as pregas vós-sinapticas parecem resistir ao processo degenerativo (seta) $(\times 10000)$. 
de JNM notou-se que, em ambos os experimentos, fibras musculares em graus avancados de necrose e desorganizacão interna permaneciam quase sempre inervadas por axónios terminais aparentemente normais (Fig. 2). Estes terminais nervosos contêm mitocôndrias, vesículas sinápticas e outras organelas de aspecto habitual e as pregas pós-sinápticas da membrana sarcolemal permaneciam aparentemente inalteradas pelo processo degenerativo. Nos animais tratados com fosfolipase A2 intramuscular notaram-se ocasionais indentacōes da membrana axonal e raras vesículas encapadas, nunca a um grau tão severo como observado em animais tratados com doses sistêmicas desta toxina (8).

3. Alterações observadas na JNM na fase crônica - Neste grupo incluimos animais tratados com fosfolipase A2 e estudados de 4 semanas a 3 meses após intoxicação, bem como camundongos ' $n d \mathrm{dx}$ ' adultos com miopatia avançada, com grande percentagem de fibras musculares regeneradas (41), Em ambas as situaçōes, as fibras musculares selecionadas apresentavam-se em fase avançada de regeneração com internalização nuclear (que persiste no camundongo como sinal de degeneracão muscular prévia) e proliferaçāo de organelas intracitoplasmáticas. Preparacões coradas para demonstrar atividade da acetilcolinesterase confirmaram que o padrão de inervação motora permanece inalterado apesar do grau avançado destas miopatias. Entretanto, a morfologia do aparelho subneural de Couteaux sofreu acentuada modificação. o padrão contínuo observado em placas terminais normais sendo totalmente substituido por padrăo fragmentado em pequenos grupos de máculas colinesterase-positivas, intercalados por áreas desprovidas de atividade enzjmática (Fig. 3). Apesar disto, estas subunidades persistiram inervando fibras musculares individuais e não se evidenciou inervação colateral. A. nivel ultraestrutural observou-se diminuição no número e complexidade das pregas pós-sinápticas de fibras musculares regeneradas (Fig. 3). O grau desta alteração pareceu ser diretamente proporcional à fase regenerativa muscular, sendo mais acentuado nos processos avançados. Estudos morfométricos com auxílio de analisador de imagem e microcomputador vieram a confïrmar estatisticamente as observacóes morfológicas obtidas a nivel ultraestrutural. conforme demonstrado na tabela 1. Os resultados indicam que nāo há diferença significativa no tamanho de uxônios terminais, densidade de vesículas sinápticas e comprimento prê-sináptico entre os animais estudados e respectivos grupos controles. Entretanto, em ambas as miopatias experimentais estudadas no presente trabalho, o comprimento pós-sináptico (que reflete o número e profundidade das pregas), a á'ea pós-sináptica do sarcoplasma e a relação entre o comprimento das membranas pós e pré-sinápticas atingıram valores marcadamente reduzidos, as vezes representando somente $50 \%$ do normal. E importante salientar ainda que raras placas terminais, mesmo em fibras regeneradas, apresentavam aparência norma!.

$x$

$\operatorname{mdx}$ 37 controle

72

FLA-IM

controle

número JNM

área pró-sináptica

área pós-sináptica

área mitocondrial

comprimento pré-sináptico

comprimento pós-sináptico

número de vesiculas

densidade vesicular

comprimento pós/prẹ́-sináptico
$6.4+5.9$

$2,1+1.5 * *$

$0.8+0.9$

$5.7+2.5$

$10-6.1 * *$

$21.3+11.3$

$374+280$

$66+30$

$1.7+0.7 * *$
$7,8+6,1$

$4,2+2,5$

$1.0+1,1$

$6.3+3.2$

$$
470+338
$$$$
75+82
$$

$3.5+1.4$
62

44
$7.8+6.7$

$3,6+3,2$

$1.3+1,2 * *$

$1,1 \div 1,2$

$0.8+0.9$

$6,5+3,9$

$5.6+3,4$

$16,9+15,1$

$8.3+5.8 * *$

$454+359$

$269+163$

$50+20$

$71 \quad-34$

$1,4+0,3$ * $*$

$2,4+1,0$

Tabela 1 - Análise morjométrica da juncão neuromuscular (JNM): mdx, camundomgo mutante 'mdx'; FLA-IM, aamundongos injettdos via intramuscular com 0,0s microgramas de fosfolipase A2 em $1 \mathrm{ml}$ de solução de Ringer; valores, média + desvio padnão; $* *, p<0,001$, Mann-Whitney; areas, micrómetros quadradas; comprimentos, micrómetros. 


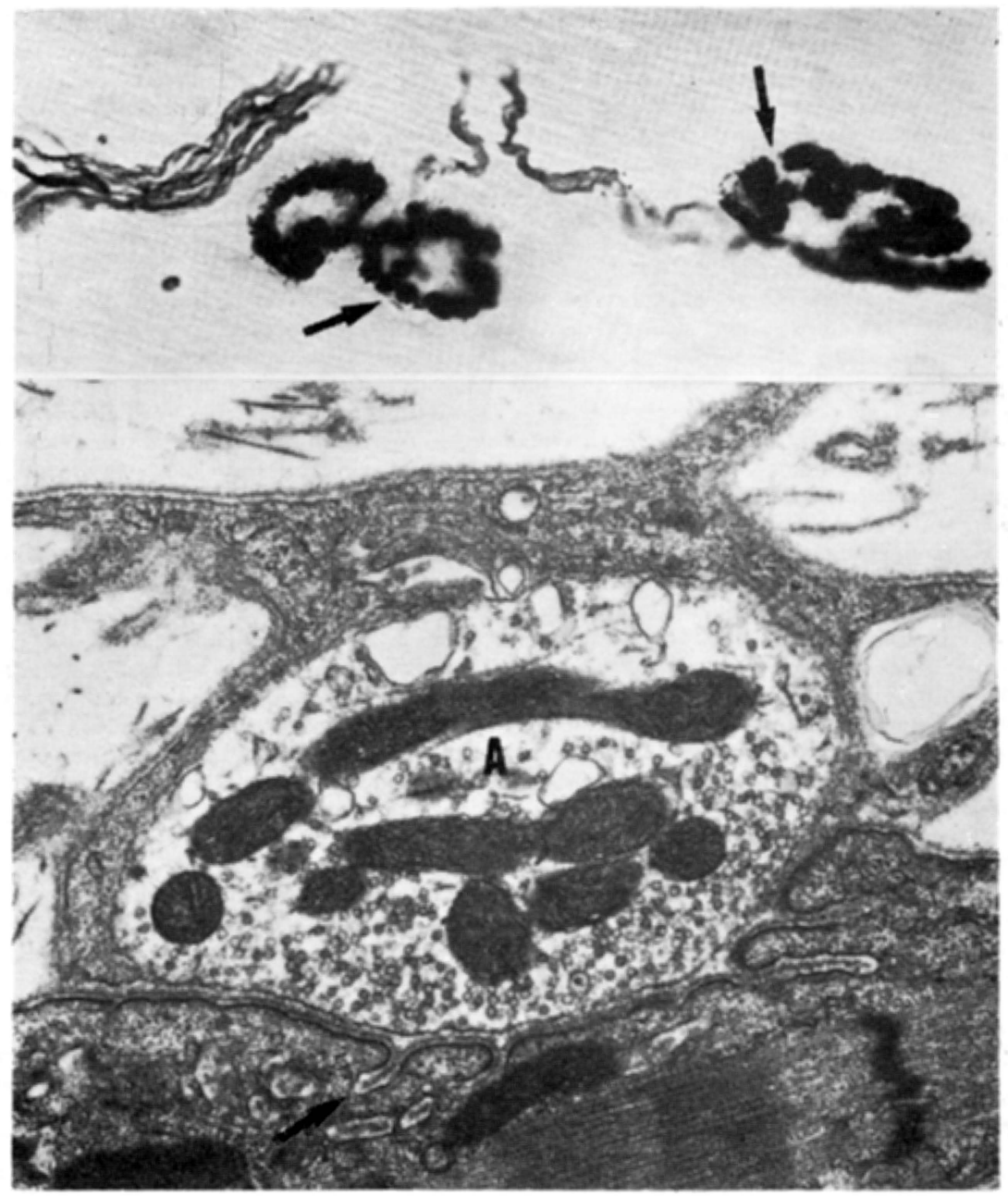

Fig. 3 - Em cima, preparação demonstrando acetilcolinesterase e axônios em músculo do camundongo ' $m d x$ ' com 4 meses de idade; notar que as diversas juncões neuromusculares apresentam-se anormais e divididas em pequenas máculas e subunidades colinesterase positivas (setas), ao invés do padrão contínuo normal; o padrã̃o de inervação permanece normal (Namba et al. $\times 400)$ : Em baixo, microscopia eletrônicia de placa mioneural em camundongo 4 meses pós-injeção de fosfolipase A2 intramuscular; o axônio terminal (A) é normal contendo mitocôndrias e vesículas sinápticas; entretanto, a membrana pós-sináptica é acentuadamente simplificada com redução do número e complexidade das pregas (seta) $(\times 20000)$.

\section{COMENTARIOS}

Existem vários tipos de miopatias em animais laboratoriais, atualmente classificados em très grandes grupos de origem: nutricionais, tóxicas e hereditárias $5,7,24,25,38$. As miopatias nutricionais foram produzidas em quase todos os tipos de mamiferos e aves, utilizando-se deficiências dietéticas de vitantina $\mathrm{E}$, ácidos graxos nâo saturados, potássio, selênio e amino ácidos sulfurados, entre outros 5 . As miopatias tóxicas podem ser induzidas por miotoxinas primárias, tais como aquelas derivadas de bactérias, artrópodes e cobras ou por diversas drogas, como hormônios, antimaláricos, antibióticos, anestésicos, narcóticos, catecolaminas 25 . As miopatias hereditárias ocorrem em diver. sas espécies animais, muitas das quais são afetadas por desordens concomitantes dos 
nervos periféricos 40. O camundongo mutante 'indx' é particularmente valioso por ser modelo laboratorial afetado por processo miopático puro sem envolvimento do sistema nervoso central ou periférico ${ }^{39-41}$. A grande maioria das miopatias mencionadas, ápesar de geradas por mecanismos totalmente distintos, determina reaçóes patológicas básicas semelhantes a nivel de fibras musculares. Nessas situações ocorre degeneraçāo muscular com alteraçōes de orgánelas como mitocôndrias, retículo endoplasmatico e miofibrilas, com eventual formação de coágulos retracionais. Tal agressão muscular é seguida por fagocitose de restos celulares, proliferação de células satélites com formaçāo de mioblastos, os quais se fundem para regenerar fibras musculares utilizando o arcabouço delimitado pela membrana basal muscular raramente afetada em tais processos.

A nível de junção neuromuscular as alterações observadas nos dois modelos miopáticos estudados no presente trabalho foram semelhantes entre si. Durante episódios de necrose muscular os axônios terminais permaneceram intactos, apesar de as fibras musculares que eles inervavam estarem totalmente desestruturadas. Em estadios mais avançados dessas miopatias, observou-se alteraçāo em JNM inervando fibras musculares regeneradas (persistência de núcleos centralizados, por distribuição irregular de acetılcolinesterase e significante redução no numero e complexidade das pregas pós-sinápticas da membrana sarcolemal. Alteraçōes semelhantes foram descritas em outras situaçōes experimentais, como após injeção de crotoxina 34 , cardiotoxima 13 , bupivacaína 23 , no camundongo mutante 'dystrophia muscularis' $2,14,28,31$, bem como em pacientes humanos com distrofia muscular tipo Duchenne 16,21. Um denominador comum à majoria das situaçóes mencionadas é que fibras musculares foram submetidas a episódios de necrose seguidos por regeneração. Este fato permite especular que a falta de diferenciaçăo da membrana sarcolemal, com consequente atrofia nas pregas pós-sinápticas, pode ser consequência direta da regeneraçáo muscular. Estudos realizados no modelo 'mdx' e em camundongos tratados com fosfolipase A2 demonstraram ausência de alterações clínicas, morfológicas e eletrofisiológicas indicativas de comprometimento neurogênico simultâneo nessas miopatias $8,39,41$. Portanto, nossas observações favorecem ainda mais a presente hipótese de que as alteraçōes observadas em JNM são provavelmente secundárias a necrose e regeneração muscular.

Os mecanismos de modulação e plasticidade da JNM permanecem desconhecidos. Sabe-se que alterações na forma e estrutura da JNM ocorrem regularmente e podem ser decorrência de influências hormonais, senilidade, doenças ou desuso 19. Por exemplo, Snell e Mclntyre 36,37 e Koenig 27 demonstraram que, após denervação, há perda e anormalidades progressivas nos locais de atividade da acetilcolinesterase muscular. Fahim e Robbins 17 e Banker et al. 1 demonstraram alterações ultraestruturais na morfologia da JNM em camundongos idosos, com idade variando de 27 a 34 meses. Entre diversos fatores influenciando a reorganização da JNM, a membrana basal parece desempenhar papel importante 4,29. A constituiçăo molecular da membrana basal juncional é diferente daquela em regiōes distantes da JNM. Na área sináptica há maior concentração de receptores de acetilcolina e canais de sódio 3,29 . Implantação de fibras nervosas motoras em áreas aneurais de fibras musculares esqueléticas induz modificação da membrana basal com formação de JNM 6,20. Nos modelos experimentais aqui estudados năo há evidência clinico-laboratorial de denervação 8,41. Portanto apesar de atrofia significativa das pregas pós-sinápticas sarcolemais devida a regeneração muscular, parece haver mecanismo adaptativo da membrana basal juncional nesses animais, a qual possivelmente concentra quantidade suficiente de receptores de acetilcolina e canais iônicos para manutenção da fisiologia normal de transmissão neuromuscular.

Finalmente, parece razoável aceitar que, em vista das observaçũes relatadas, a exuberante quantidade de pregas pós-sinápticas normalmente encontrada nas JNM deve representar mecanismo anatômico de segurança na transmissão química nervosa. Esta hipótese explicaria porque fibras musculares, contendo aproximadamente metade do comprimento de membrana pós-sináptica, são ainda capazes de manter função aparentemente normal.

Ayradecimentos - Este trabalho resulta de observacões feitas durante Tese de $P h D$ realizada no Departamento de Neuropatologia, Instituto de Neurologia, Universidade de Londres, Inglaterra, com apoio financeiro do CNPq. Agradecemos profundamente a supervisão do Prof. L.W. Duchen e, aos Drs. G. Brook e F. Gopalakrishnakone, por estudos colaborativos. 


\section{REFERENCIAS}

1. Banker BQ, Kelly SS, Robbins $\mathrm{N}-$ Neuromuscular transmission and correlative morphology in young and old mice. $J$ Physiol 339:355, 1983.

2. Banker BQ, Hirst NS, Chester CS, Fok RY - Histometric and electron cytochemical study of muscle in the dystrophic mouse. Ann New York Acad Sci 317:374, 1979.

3. Beam KG, Caldwell JH, Campbell DT - Na channels in skeletal muscle concentrated near the neuromuscular junction. Nature 313:588, 1985.

4. Betz W, Sakmann B - Effects of proteolytic enzymes on function and structure of frog neuromuscular junctions. J Physiol 230:673, 1973.

5. Blaxter KL - Myopathies in animals. In Walton J: Disorders of Voluntary Muscle. Churchill Livingstone, Edinburgh, 1974.

6. Bowden, REM, Duche LW - The anatomy and pathology of the neuromuscular junction. In Zaimis E: Handbook of Experimental Pharmacology. Springer, Berin, 1976.

7. Bradley $\mathbf{R}$, Fell $\mathbf{B F}$ - Myopathies in animals. In Walton $\mathbf{J}$ : Disorders of Voluntary Muscle. Churehill Livingstone, Edinburgh, 1981.

8. Brook G, Torres LF, Gopalakrishnakone P, Duchen LW - Effects of phospholipase of Enhydrina schistosa venom on nerve, motor end-plate and muscle of the mouse. Quart $J$ Experi Physiol 72:571, 1987.

9. Buchthal F, Schmalbruch $\mathrm{H}-$ Motor unit of mammalian muscle. Physiol Rev 60:90, 1980.

10. Coers C - Morphologie de la jonction neuro-musculaire. Arch Biol (Liege) 75 (suppl): 905, 1964 .

11. Couteaux $\mathrm{R}-$ Morphological and cytochemical observations on the post-synaptic membrane at motor end-plates and ganglionic synapses. Exper Cell Res 5 (suppl):294, 1958.

12. Duchen LW - An electron microscopic comparison of motor end-plates of slow and fast skeletal muscle fibres of the mouse. J Neurol Sci 14:37, 1970.

13. Duchen LW, Excell BJ, Patel R, Smith B - Changes in motor end-plates resulting from muscle fibre necrosis and regeneration: a light and electron microscopic study of the effects of the depolarizing fraction of Dendroaspis jamesoni venom. J Neurol Sci $21: 391,1974$.

14. Ellisman MH - The membrane morphology of the neuromuscular junction, sarcolemma, sarcoplasmic reticulum and transverse tubule system in murine muscular dystrophy studied by freeze-fracture electron microscopy. Brain Res 214:261, 1981.

15. Engel AG, Santa $\mathbf{T}$ - Histometric analysis of the ultrastructure of the neuromuscular junction in myasthenia gravis and in the myasthenic syndrome. Ann New York Acad Sei $183: 46,1971$.

16. Engel AG, Jerusalem F, Tsujihata $M$, Gomez MR - The neuromuscuiar junction in myopathies: a quantitative ultrastructural study. Recent Advances in Myology 360:132, 1974.

17. Fahim MA, Robbins $\mathbf{N}$ - Ultrastructure studies of young and old mouse neuromuscular junctions, J Neurocytol 11:641, 1982.

18. Fardeau M - Ultrastruture des jonctions neuromusculaires dans la musculature squélettique du cobaye. In Israel $M$, Manaranche $R$ : La Transmission Cholinergique de L'Excitation. Inserm, Paris, 1973.

19. Grinneil AD, Herrera AA - Specificity and plasticity of neuromuscular connections: long-term regulation of motor neuron function. Progress in Neurobiol 17:203, 1981.

20. Gwyn DG, Aitken JT - The formation of new end-plates in mammalian skeletal muscle. J Anatomy 1C0:116, 1966.

21. Harriman DGF - A comparision of the fine structure of motor end-plates in Duchenne dystrophy and in human neurogenic diseases. $J$ Neurol Sci 28:233, 1976. 
22. Hopkins WG, Brown MC, Keynes RJ - Postnatal growth of motor nerve terminals in muscles of the mouse. J Neurocyt 14:525, 1985.

23. Jirmanova I - Ultrastructure of motor end-plates during pharmacologically induced degeneration and subsequent regeneration of skeletal muscle. $J$ Neurocytol $4: 141,1975$.

24. Kakulas BA - Experimental Myopathies. In Walton J: Disorders of Voluntary Muscle. Churchill Livingstone, Edinburgh, 1981.

25. Kakulas BA - Toxic and drug-induced myopathies. In Mastaglia FL, Walton J: Skeletal Muscle Pathology. Churchill Livingstone, Edinburgh, 1982.

26. Karnovsky MJ - A formaldehyde-gluraraldehyde fixative of high osmolarity for use in electron microscopy. J Cell Biol 27:137A, 1965.

27. Koenig $J$ Morphogenesis of motor' end-plates 'in vivo' and 'in vitro'. Brain Res 62:361, 1973.

28. Law PK, Saito A, Fleischer S - Ultrastructural changes in muscle and motor end-plate of the dystrophic mouse. Exper Neurol 80:361, 1983.

29. McMahan UJ, Edgington DR, Kuffler DP - Factor that influence regeneration of the neuromuscular junction. $J$ Exper Biol $89: 31,1980$.

30. Namba T, Nakamura T, Grob D - Staining for nerve fibre and cholinesterase activity in fresh frozen sections. Am J Clin Pathol 47:7.1, 1967.

31. Ontell M, Haller E - Necrotic extrafusal muscle fibres of the dystrophic mutant mouse: the ultrastructure of the myoneural junction. Anat Rec 197:397, 1980.

32. Padykula HA, Gauthier GF - The ultrastructure of the neuromuscular junction of mammalian red, white and Intermediate skeletal muscle fibres. J Cell fiol 46:27, 1970.

33. Pestronk A, Drachman D - A new stain for quantitative measurement of sprouting at neuromuscular junctions. Muscle and Nerve 1:70, 1978.

34. Queiroz LS - Effects of neurotoxins on muscle and nerve in the mouse: morphological and physiological studies. Tese $\mathrm{PhD}$. Universidade de Londres, Inglaterra, 1981.

35. Santa T, Engel AG - Histometric analysis of neuromuscular junction ultrastructure in rat red, white and intermediate muscle fibres. In Desmedt $J E$ : New Developments in EMG and Clinical Neurophysiology. Karger, Basel, 1973.

36. Snell RS, Mcintyre $\mathrm{N}$ - Effect of denervation on the histochemical appearance of cholinesterase at the myoneural junction. Nature 176:884, 1955.

37. Snell RS, McIntyre $N$ - Changes in the histochemical appearances of cholinesterase at the motor end-plate following denervation. $\mathrm{Br} \mathrm{J}$ Exper Pathol 37 (1), 1956.

38. Telford IR, Einarson L - Experimental muscular dystrophies in animals. Charles Thomas, USA, 1971.

39. Torres LFE - Muscle, motor end-plate and nerves in hereditary and experimental myopathies in the mouse. Tese PhD. Universidade de Londres, Inglaterra, 1986.

40. Torres LFB - Inherited neuromuscular diseases in the mouse: a review of the literature. Arq Neuro-Psiquiat (São Paulo) 46:298, 1988.

41. Torres LFB, Duchen LW - The mutant 'mdx': inherited myopathy in the mouse. Morphological studies of nerves, muscles and end-plates. Brain 110-269, 1987.

42. Waerhaug $O$, Korneliussen $H$ - Morphological types of motor nerve terminals in rat hindlimb muscles, possibly innervating different muscle fibre types, $Z$ Amat Entwicklungs-gesch (Berlin) 144:237, 1974. 